\title{
Optimization of oyster (P leurotus ostreatus) mushroom cultivation using locally available substrates and materials in Debre Berhan, Ethiopia
}

\author{
Asmamaw Tesfaw ${ }^{1}$, Abebe Tadesse ${ }^{1}$, Gebre Kiros ${ }^{2}$ \\ ${ }^{1}$ Department of Biology, Debre Berhan University, Debre Birhan, Ethiopia. \\ ${ }^{2}$ Department of Plant Science, Debre Berhan University, Debre Birhan, Ethiopia.
}

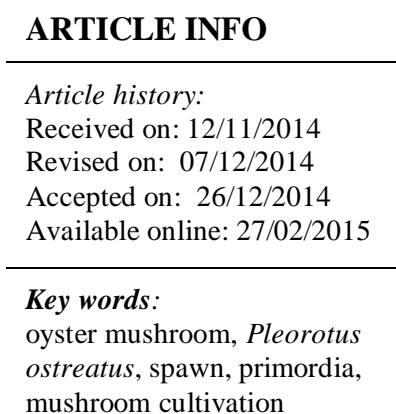

\section{INTRODUCTION}

Pleurotus species, commonly known as oyster mushrooms, are edible fungi cultivated worldwide especially in south east Asia, India, Europe and Africa [1]. China produces 64 $\%$ of all edible mushrooms in the world and $85 \%$ of all oyster mushrooms all over the world (Pleurotus spp.) is also produced in China [2]. Oyster mushrooms is the third largest [3] commercially produced mushroom in the world; however, Sánchez [4] reported that $P$. ostreatus is the second largest next to Agaricus bisporus in the world market. Mushroom cultivation is the fifth largest agricultural sector in China with 24 billion USD value and $10 \%$ growth rate every year for the last 30 years [5]. Oysters are naturally found on rotten wood material. The growing and consumption interest of oyster mushroom is increasing largely due to its taste, medicinal and nutritional properties [6]. Large volumes of unused lignocellulosic byproducts are available in tropical and sub tropical areas. These by-products are left to rot in the field or are disposed off through burning. Utilizing these by-products for mushroom cultivation using locally available technologies may be one of the solutions to transforming these inedible wastes into accepted edible biomass of high market value.

* Corresponding Author

Asmamaw Tesfaw,Email: astesfa@yahoo.com

Cell phone: +251911956817 , P.O. Box 445 Debre Berhan, Ethiopia
The spent substrates from mushroom cultivation can also potentially be used as an animal feed supplement, possibly providing additional animal feed resources [3]. A shorter growth time is required to $P$. ostreatus in comparison to other edible mushrooms. The substrate used for their cultivation does not require sterilization, only pasteurization, which is less expensive. High percentage of the substrates can be converted to fruiting bodies by oyster mushroom and hence it increases profitability.

$P$. ostreatus demands few environmental controls, and their fruiting bodies are not often attacked by diseases and pests, and they can be cultivated in a simple and cheap way [4]. All this makes $P$. ostreatus cultivation an excellent alternative for production of mushrooms when compared to other mushrooms. Therefore, it is better for unskilled farmers than other mushrooms. Mushroom cultivation provides an alternative employment and it contributes food security to rural disadvantaged groups especially women and old people in Tanzania hence improve their livelihood [7]. The expansions of mushroom cropping decline the price of mushrooms and hence it safe guard food insecurity [5].

Debre Berhan is located in North Shewa Administrative Zone, Amhara Region and it is $130 \mathrm{Km}$ North to the Capital City, Addis Ababa. Debre Berhan is the coldest and windy town in the country with an elevation of 2,850 meters above sea level. According to World Bank [8], North Shewa is under high risk for drought and hence the zone needs an alternative agricultural practice that can't be easily affected by climate change. 
Oyster mushroom cultivation is best in this regard since it doesn't require fertile soil and natural rain unlike other crops in Ethiopia. The aim of this research is to evaluate optimum conditions for oyster (Pleurotus ostreatus) cultivation using locally available substrates, materials and technologies.

\section{MATERIALS AND METHODS}

\subsection{Potato dextrose agar (PDA)}

PDA was prepared from locally available fresh potato and industrially produced agar and glucose. About $200 \mathrm{~g}$ of potato was washed and sliced and placed in 1 liter of boiling water in a flask like brass locally available and boiled for 15 minutes. Potato broth was filtered using a piece of cloth. Glucose $(20 \mathrm{~g})$ and $20 \mathrm{~g}$ agar was added and the volume was adjusted to one liter by adding water. The flask was plugged with absorbent cotton. The agar mixture and petridishes were sterilized in pressure cooker for 30 minutes. The agar $(25 \mathrm{ml})$ was poured carefully and aseptically in to petridishes around flame and for comparison, the laminar air flow hood was also used. After cooling, the PDA was used for $P$. ostreatus inoculation and incubated at $25^{\circ} \mathrm{C}$ and at ambient temperature.

\subsection{Spawn production}

The grains, such as sorghum, wheat and dried malt wheat, were cleaned manually to remove inert matter, stubble and debris. The cleaned grains were soaked in tap water overnight. In addition, the grain was boiled soon after soaking for urgent spawn preparation. Thereafter, the soaked grains were drained and the excess water was removed and the following additives were added. Wheat bran at the rate of $10 \%$, and chalk $\left(\mathrm{CaCO}_{3}\right)$ at the rate of $2 \%$ were added on dry weight basis of the grains. The additives were thoroughly and evenly mixed with the grains. The grain medium was filled in to bottles (made of brass) locally found. The bottles were covered using cotton wool plugged conduit. The bottles with spawn materials were autoclaved using pressure cooker and the supporting materials in bottles were allowed to cool for over six hours. The media in bottles were immediately inoculated with mycelial culture of $P$. ostreatus maintained on PDA. For successive production of spawn, the media in the bottles were inoculated with $P$. ostreatus. Then, it was incubated at $25^{\circ} \mathrm{C}$ for mycelial growth without any light for 10-15 days until the mycelium fully covered the grains. It was shaken every four days to distribute mycelium throughout the grain till the end of the growing day. Alternatively, the grains were put on bench at varying ambient temperature $\left(12-19^{\circ} \mathrm{C}\right)$.

\subsection{Substrate preparation}

Wheat straw, barely straw, saw dust and sinar straw were collected from Debre Birhan surroundings and 90\% of each substrate on dry basis were measured and soaked in tap water overnight to moisten and make the substrate soft for colonization to oyster mushroom hyphae. Alternatively $3 \%$ gypsum, chalk or $\mathrm{CaCO}_{3}$ was added to $10 \%$ wheat bran. The buffer and wheat bran were mixed separately and then they were added to the substrates.
In addition to different substrates, different supplements were also evaluated to observe their impact on oyster growth. Oil seed cake, wheat bran and cow dung (10\% on dry basis) were added to $90 \%$ wheat straw and saw dust separately to ensure the even distribution of materials. Then the substrates and supplements were well mixed after the supplements and buffers were separately mixed. The relative humidity after mixing was measured as

Relative Humidity

$=\frac{\text { weight of moistened substrate }- \text { weight of dry substrate }}{\text { weight of moistened substarate }} \times 100 \%$

\subsection{The growth of oyster on organic wastes}

Many waste papers are released and burnt every month in Debre Berhan University. Hence an attempt to use waste paper as a medium for oyster cultivation was evaluated. Different amount of waste papers was mixed with saw dust. Saw dust (100\%) was used as a control. In addition, in all $10 \%$ wheat bran was added after it was mixed with $3 \%$ gypsum separately. Finally the growth and the yield were measured using pileus diameter and biological efficiency. The $P$. ostreatus was inoculated and placed at ambient temperature. Gabi is, the Ethiopian traditional clothe and made of woven cotton, commonly dressed in the country. No clothe as frequently used as gabi by the majority of the people in the country and hence too much gabi wastes can be released every year in the country. Trials were made to cultivate the $P$. ostreatus on gabi wastes. Here $100 \%, 75 \%, 50 \%, 25 \%$, and $0 \%$ saw dust were added to $0 \%, 25 \%, 50 \%, 75 \%$ and $100 \%$ gabi wastes respectively. In addition, $10 \%$ wheat bran and 3\% gypsum were added. The percentage was calculated on dry basis. The substrates were pasteurized using oil drum. After cooling for an hour, the substrates was inoculated with $P$. ostreatus and placed at ambient temperature.

\subsection{Reuse of the Substrates}

The substrates that were used for cultivation of oyster for 2 flushes were used again for other cultivation. Here substrates were utilized in two ways. On the first hand, substrates without adding anything on used substrates were taken to grow mushrooms. On the other hand, $10 \%$ wheat bran and $2 \%$ gypsum was added to the used substrates. In addition, they were pasteurized in steam and sterilized using autoclave to evaluate the effect of contaminants that were presented in used substrates.

\subsection{Spawning}

The wooden hood and hands were disinfected with $70 \%$ alcohol. The mixer rod was sterilized by flame locally made. Then, the pasteurized substrates were inoculated with 4-6\% P. ostreatus seed aseptically from mother spawn and they were incubated at $25^{\circ} \mathrm{C}$ and ambient temperature.

\subsection{Effect of pore size}

After substrates were filled to plastic bags, different size holes were made to evaluate effect of aeration, contamination and moisture loss. Pine holes, $16.18 \mathrm{~mm}^{2}$ and $28.16 \mathrm{~mm}^{2}$ holes were made using circular cutter with different diameter. Here pine holes 
were made after substrates were filled in the bags. However $16.18 \mathrm{~mm}^{2}$ and $28.16 \mathrm{~mm}^{2}$ holes were made before substrate were placed to the containers. The one with pin hole was arranged in two ways. First it was tied at top and second cotton plug was attached to plastic at the top to allow more aeration.

\subsection{Effect of temperature}

Since Debre Birhan is relatively cold especially from end of September to January, effect of ambient temperature on yield of oyster was evaluated since farmers in rural area are not able to buy incubators. Here, the bottle method was used due to its easiness to handle in the incubator. Equal amounts of substrates were put into two bottles. After inoculation, one was placed in the incubator at $25^{\circ} \mathrm{C}$ and the other was put on bench. The bench temperature was varying from $3^{\circ} \mathrm{C}$ to $19^{\circ} \mathrm{C}$. Then every week the growth and development of oyster mycelium was physically observed and assessed.

\subsection{Pinhead initiation}

Light and temperature were used to initiate the formation of pinheads after the mycelium was fully grown on the substrate i.e. after the substrate was fully turned into white color due to mycelium mass. The growing mycelium that was placed in dark was brought to a fully illuminated region; on the other hand, the bottles and plastic bags that were put in the incubator at $25^{\circ} \mathrm{C}$ were placed at ambient temperature. The ambient temperature, when the experiment was conducting, was varying from $3^{\circ} \mathrm{C}$ to $19^{\circ} \mathrm{C}$.

\subsection{Fruiting}

When the substrate was completely covered by the mycelium, the cotton plug was removed. Top of the plastic bag was partially removed. In addition, the part of the plastic that covered the primordia was also removed without harming the mycelium. The plastic bags that contain primordia was sprayed with water three times a day to increase the relative humidity [9].

\subsection{Biological efficiency (yield)}

Biological efficiency is a measureable tool used to know the growth potential of the oyster mushroom. It is calculated based on the following formula.

$$
\text { Biological efficency }=\frac{\text { weight } \text { of freish mushroom }}{\text { dry weight of substrate }} \times 100 \%
$$

\section{RESULTS AND DISCUSSIONS}

\subsection{Oyster culture on PDA}

PDA is the simplest and the most popular medium for growing mycelia of most cultivated mushrooms [2]. P. ostreatus was successfully grown on PDA. The oyster completely covered the petridishes in 9 days and its color and appearance looks like pure cotton (fig 1). The mycelium should be white and grow out from the tissue. If yellow, blue, green or grey mycelia form on other places on the surface, then these are fungal contaminants
[10]. A creamy, shiny growth often indicates bacterial contamination [10]. P. ostreatus is a slow grower when it is compared to molds and other fungi.
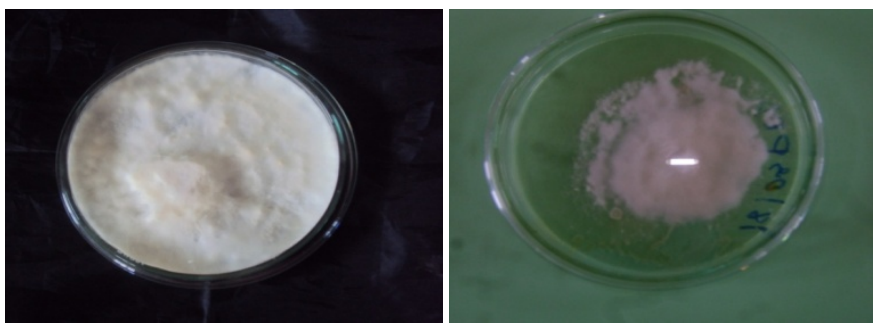

Fig. 1: P. ostreatus culture on PDA 5 days old (right) and 11 days old (left).

\subsection{Oyster spawn}

Once a pure culture of mushroom is obtained, the spawn could be made from it. The spawn is the mycelium of the mushroom on a solid material. Functionally, it is the starter inoculums of mushroom cultivation. Solid materials such as saw dust, whole grain of cereals, shredded maize and corn cobs etc are used for spawn preparation [9].

$P$. ostreatus was grown on sorghum wheat, and dried malt wheat based spawn without showing significant preference on them. Sorghum and wheat are cheap in Debre Birhan market hence it is economical to use them to produce spawns. The choice of grain is made after considering several factors such as its prevailing price, easy supply and grain size. In some areas in Africa, sorghum is better available and cheaper than maize [9].

Besides, the space between wheat or sorghums is quite enough for air circulation. However if teff was used, there would be no good aeration and teff seeds also get clamped together during sterilization [9]. That is why oyster didn't grow very well in spawn that contain too much wheat bran especially at the bottom of the flask (data not shown).

The whole inoculated cereals put on incubator at $25^{\circ} \mathrm{C}$ were covered by mycelium of $P$. ostreatus within 14 days. However, those placed at bench took 22 days to colonize the cereal grains. Therefore, it is possible to prepare spawn without incubator, by simply placing on bench even if it takes longer period relatively.

Sorghum needs longer time to imbibe the same amount of water than wheat [9]. That is why sorghum was boiled but the sorghum should not be burst because the burst sorghum will be clamped and then it reduces the air circulation due to starch exposure during bursting.

Oei [11] compared the advantage and disadvantage of grains over sawdust or wooden stick. The main advantage of grains is that it is very nutritious for fungi and form kernels easily. The kernels can easily be distributed to the substrate. The main disadvantage is that it provides optimal substrate for other organisms too. The chances of contaminations are therefore much higher compared to sawdust or wooden stick spawns.

The moisture content of the grain should be around $50 \%$ [11]. However, Dawit [9] stated that water content of $40-60 \%$ is optimal for spawn making. In our case, the water content was 
$52 \%$. If the water content is higher, mycelia growth may be faster but the danger of wet spot bacteria is also greater. If it is drier than $35 \%$, mycelia growth will be slow [11]. To get good quality of spawn, what is most important is the quality of the inoculums. The inoculums should be fresh and pure. If the inoculums are preserved in refrigerator, they should be activated before they are used for spawn production.

\subsection{Substrates}

Mushroom cultivation is different from conventional agriculture in one major point. The soil in the ground is the substrate for production of crops but the mushrooms grow on lignocellulosic agro industrial wastes. Oyster can grow on wide agricultural wastes what matter is which agricultural residues are found around us [9].

Wheat straw, barely straw, sinar straw and saw dust were used as substrates for $P$. ostreatus. There was no significant biological efficiency difference on the substrates (table 1). It was successfully grown on them. Dawit [9] and Oei [11] pointed out that Pleurotus can grow on wheat and barley straws.

The moisture content of the substrates was varying from $69.8 \%$ to $74.5 \%$. Significantly the highest run rate was recorded at $70 \%$ moisture level [12]. $\mathrm{pH}$ of the straw before adding chalk and gypsum was 5.8 .This might be because of the acids produced by microbes in substrates during soaking of substrates in water since it was soaked overnight. However, the $\mathrm{pH}$ rose to 6.9 when chalk was added. Here, washing is essential to neutralize the $\mathrm{pH}$ of the substrate. In addition, the chalk neutralizes the lowered $\mathrm{pH}$. Furthermore, chalk and gypsums act as buffer. Besides, the $\mathrm{Ca}^{2 \mathrm{t}}$ obtained from gypsum $\left(\mathrm{CaSO}_{4}\right)$ and chalk $\left(\mathrm{CaCO}_{3}\right)$ neutralize oxalic acid produced during mycelial growth [9]. Highest yield is observed at $\mathrm{pH} 7$ even though there is no significant yield difference at the $\mathrm{pH} 6-8[13,14]$. However, the biological efficiency, biological yield and economic yield were increased with the increase of $\mathrm{pH}$ levels up to 5.04 and then decreased [12]. On contrary, Nwokoye et al. [15] showed that P. ostreatus was able to grow optimally at $\mathrm{pH}$ of 9.

Oyster productivity difference when different buffer such as gypsum, chalk and pure $\mathrm{CaCO}_{3}$ were optimized; they showed no difference on oyster yield. However, there was $\mathrm{pH}$ difference after they were added (table 2).

Supplements are additives which increase the yields by providing specific nutrients for the growth of the mycelium [9, 11]. However, supplements increase the risk of contamination at least by $25 \%$ [16] since supplements also provide good nutrients to other microorganisms. Dawit [9] also stated that supplements change physical conditions of substrates more suitable for cultivation of mushrooms. Addition of supplements (rice husk) to waste paper significantly increase spawn running, pin head formation, fruit body formation and mushroom yield [17]. Similarly, cultivation of oyster mushroom on wheat straw and bagasse amended with distillery effluent yield better result than substrates without distillery [18] effluent. The effects of wheat bran, oil seed cake (fig 2) and cow dung on growth were evaluated and it was found that oil seed cake gave maximum yield (table 1 and fig 2). Likewise, Ruiz-Rodriguez et al. [19] found that oyster yield increased on substrates with supplementation of oil mill waste without affecting cultivation parameters. The yield reduction in cow dung might be due to contamination since pasteurized substrates containing caw dung was partly contaminated by green mold.. Similarly, Baysal et al. [17] proposed that the yield reduction in oyster production during supplimenattion of peat and chicken manure might be due to high nitrogen content of the substrate.

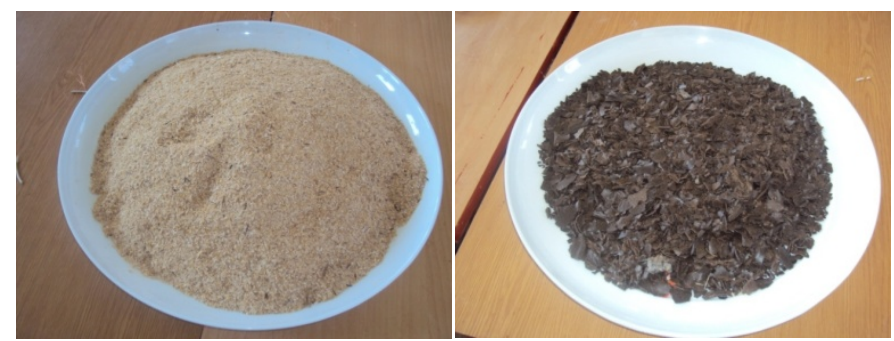

Fig. 2: Supplements: wheat bran (left) and oilseed cake of niger seed (right)

The substrates used for cultivation of oyster were used again for other cultivation. The pasteurized substrates were found to be contaminated. However, $P$. ostreatus was grown in noncontaminated parts. As it is indicated in table 1 , reused substrates that contained additional supplements exhibited better growth on both pasteurized and sterilized substrates. The yield decrease in reused substrate is because $P$. ostreatus is primary decomposer. The reused substrates were very soft and made into small pieces easily. Therefore, the aeration in reused substrates will be relatively lower than original substrates. Furthermore, biological efficiency of oyster was evaluated using waste paper and gabi wastes and it was found that waste paper and gabi were better than wheat straw (fig 3).

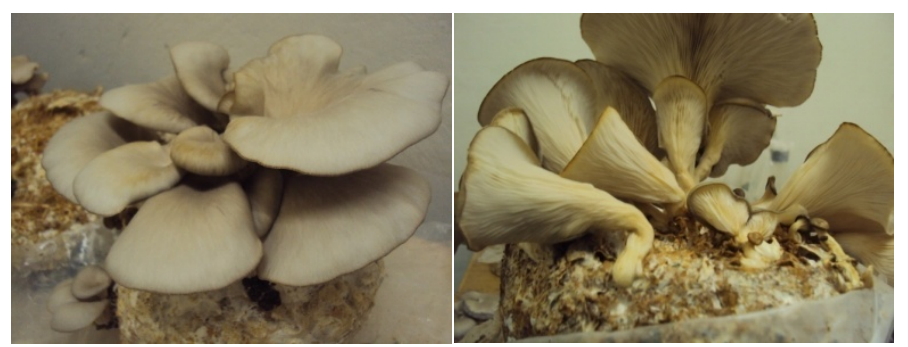

Fig. 3: Oyster in gabi waste alone (left) and saw dust with gabi waste (right).

In order to find why gabi and waste paper gave maximum yield, moisture holding capacity of the substrates were evaluated and the waste paper and gabi had high water holding capacity. Hence one reason for high yield of oyster in gabi and waste paper might be its high water holding capacity. Oyster cultivation on shredded office paper and cardboard yielded more edible sporophore biomass than other lignocellulosic residues [1].

\subsection{Effect of pore size}

Pin holes, $16.18 \mathrm{~mm}^{2}$ and $28.16 \mathrm{~mm}^{2}$ holes were made on plastic bags to evaluate the effect of aeration, contamination and 
moisture loss. Substrate in plastic with pin holes and $16.18 \mathrm{~mm}^{2}$ holes were well colonized by $P$. ostreatus. However, the yield was lower in bags with $16.18 \mathrm{~mm}^{2}$ (table 1). On plastic bag with $28.16 \mathrm{~mm}^{2}$ areas around the holes were not colonized and it was contaminated by molds. Inability to colonize might be due to great loss of moisture since the hole is large enough.

\subsection{Effect of temperature}

The substrates in the bottle placed in the incubator at $25^{\circ} \mathrm{C}$ were colonized by oyster within 15 days where as the one put at beach with temperature varying from 3 to $19^{\circ} \mathrm{C}$ was colonized within 21 days. At the temperature below $14^{\circ} \mathrm{C}$, the growth of the oyster was found to be so slow that they couldn't give primordia within 28 days. In stead 46 days were required for pinhead formation at temperature below $14^{\circ} \mathrm{C}$ and the yield was also very small (table 1). To increase the temperature, the room was heated using wood charcoal. For most mushrooms, mycelial invasion is favored at higher temperature and fruit body formation at relatively lower [9, 11]. On the other hand, Alam et al. [14] investigated that the maximum growth is recorded at $25{ }^{\circ} \mathrm{C}$ and the lowest at $15^{\circ} \mathrm{C}$ and no significance difference is observed between $25{ }^{\circ} \mathrm{C}$ and $30{ }^{\circ} \mathrm{C}$. Therefore, the temperature ranging between 25 $30{ }^{\circ} \mathrm{C}$ is best for mycelial growth of $P$. ostreatus. However, edible mushrooms cultivated between $15-20{ }^{\circ} \mathrm{C}$ present better quality and durability than those at $25{ }^{\circ} \mathrm{C}$ [20]. In addition, P. ostreatus grew faster at $30{ }^{\circ} \mathrm{C}[20]$. In general, oyster yield decreases when the temperature decreases in different climatic zones of Pakistan [21].

\subsection{Pin head initiation}

Light and temperature changes were used to facilitate pinhead formation. Humidity and $\mathrm{CO}_{2}$ concentration adjustment is also essential. All oyster mushrooms need light for the proper development of cap. Usually there is enough light for oyster [11] if it is possible to read a news paper in the growing room. Pin heads were developed in 26-31 days. P. ostreatus completed spawn running in 17-20 days on different substrates and time for pinheads formation was noted as 23-27 days [22]. In addition, temperature plays very important role for pin head formation. That is why pinhead evolvements were failed at a temperature lower than $11^{\circ} \mathrm{C}$. Furthermore, humidity should be very high during primordia formation. To achieve it, the mycelium was sprayed with water 3 times a day. Oei [11] stated that humidity at time of induction must be $\geq 90 \%$. In some countries like Philippines and Nepal growers take off all or almost all the plastic from the bags. This leads to fast drying out of the substrate and lower the yields and hence it should be discouraged [11]. Another disadvantage of removing plastic is that more but smaller fruit bodies are formed, which increases the picking cost considerably.

\subsection{Harvesting}

At the first trial, only the first flush was harvested and $2^{\text {nd }}$ and other flush were failed. These motivated us to see different environmental conditions and when the mycelium were covered by plastic after spraying with water, pinheads were developed and then $2^{\text {nd }}, 3^{\text {rd }}$ and $4^{\text {th }}$ flushes were also successfully cultivated. Hence, what is most important for $2^{\text {nd }}, 3^{\text {rd }}$ and $4^{\text {th }}$ flushes cultivation is humidity. Furthermore, temperature also affected our $2^{\text {nd }}, 3^{\text {rd }}$, and $4^{\text {th }}$ flushes (data not shown).

Unlike many other mushrooms by which the yield continuously decrease in consequent flushes, the pattern of $P$. ostreatus is different. More yields were found in second flushes (table 1). The highest crop of the mushroom is obtained during the second and third flush [9]. However, the maximum yield was obtained in first flush than the second and third flush [22]. In general, one crop of mushroom with four flushes is most economical. It is unwise to keep spawn running of substrate for longer than 90 days as the yield significantly decrease.

Good control of the humidity during cropping is very important for all types of mushroom. The moisture content of growing mushroom media is a very important factor; hence, the proper moisture content value encourages the growth, while higher or lower ones had a negative effect on growth [23]. It is good keep the humidity high $(80-90 \%)$ by spraying water several times per day [10]. However, no water should be sprayed directly onto mushrooms that are ready for picking; their shelf life will decrease drastically if they become too wet [9].

Table 1: Oyster yield with varying substrates, supplements, pore sizes, temperature, reused substrate and flushes.

\begin{tabular}{|c|c|c|c|c|}
\hline Experimentation & BE\% & Experimentation & & BE\% \\
\hline Substrates & & Effect of temperature & & \\
\hline Wheat straw & 68.16 & Temperature & Primordia days & $\mathrm{BE} \%$ \\
\hline Sinar straw & 66.02 & 3 to $19^{\circ} \mathrm{C}$ (ambient) & 46 days & 65.44 \\
\hline Barely & 65.52 & $25^{\circ} \mathrm{C}$ & 28 days & 71.59 \\
\hline Saw dust & 66.31 & Effect of reused substrate with different heat treatment & & \\
\hline Supplements & & Reused substrates & Heat treatment & $\mathrm{BE}$ \\
\hline Wheat bran & 64.21 & Used substrate & Pasteurization & $21.54 *$ \\
\hline Oil seed cake (Niger seed) & 71.56 & Used substrate and supplements & Pasteurization & $28.18^{*}$ \\
\hline Cow dung & $12.32 *$ & Used substrate & Sterilization & 39.39 \\
\hline Pore size & & Used substrate and supplements & Sterilization & 54.02 \\
\hline Pin holes & 62.31 & & & \\
\hline $16.18 \mathrm{~mm}^{2}$ & 60.02 & & & \\
\hline $28.16 \mathrm{~mm}^{2}$ & $28.79 *$ & & & \\
\hline Flushes & & & & \\
\hline First flushes & 18.24 & & & \\
\hline Second flushes & 24.67 & & & \\
\hline Third flushes & 16.92 & & & \\
\hline Fourth flushes & 10.22 & & & \\
\hline
\end{tabular}

*Was found to be contaminated 
Table 2: Effect of buffer on wheat straw substrate.

\begin{tabular}{lccc}
\hline \multicolumn{1}{c}{ Buffer } & $\begin{array}{c}\text { Initial } \\
\text { pH }\end{array}$ & $\begin{array}{c}\text { pH after addition } \\
\text { of buffer }\end{array}$ & $\begin{array}{c}\text { Biological } \\
\text { efficiency }\end{array}$ \\
\hline Gypsum & 5.8 & 6.87 & 59.23 \\
Chalk & 5.8 & 6.93 & 60.19 \\
Pure $\mathrm{Na}_{2} \mathrm{CO}_{3}$ & 5.8 & 7.02 & 58.77 \\
\hline
\end{tabular}

\section{CONCLUSIONS}

Relative humidity, aeration, temperature, and contaminations are most important factors during oyster cultivation in Debre Berhan using locally available substrates, materials and technologies. Even though oyster spawning grow best at $25^{\circ} \mathrm{C}$, it is possible to cultivate it at lower temperature. Drying the substrates greatly reduce the yield hence spraying it with water is mandatory. To activate $2^{\text {nd }}, 3^{\text {rd }}$, and $4^{\text {th }}$ flush, covering the substrates with plastic is very important to make the substrate moist. Gabi and paper wastes can be used as a substrate separately or in mixture with saw dust. Generally, oyster can be cultivated in Debre Berhan with locally available materials without using sophisticated lab equipment for spawn production.

\section{ACKNOWLEDGMENT}

This research was financially supported by Research Directorate, Debre Berhan University.

\section{REFERENCES}

1. Mandeel Q, Al-Laith A, Mohamed S. Cultivation of oyster mushrooms (Pleurotus spp.) on various lignocellulosic wastes. World Journal of Microbiology and Biotechnology. 2005;21(4):601-7.

2. Chang S-T. World Production of Cultivated Edible and Medicinal Mushrooms in 1997 with Emphasis on< i> Lentinus edodes $</ \mathrm{i}>$ (Berk.) Sing, in China. International Journal of Medicinal Mushrooms. 1999;1(4):291-300.

3. Obodai M, Cleland-Okine J, Vowotor K. Comparative study on the growth and yield of Pleurotus ostreatus mushroom on different lignocellulosic by-products. Journal of Industrial Microbiology and Biotechnology. 2003;30(3):146-9.

4. Sánchez C. Cultivation of Pleurotus ostreatus and other edible mushrooms. Applied microbiology and biotechnology. 2010;85(5):1321-37.

5. Zhang Y, Geng W, Shen Y, Wang Y, Dai Y-C. Edible Mushroom Cultivation for Food Security and Rural Development in China: BioInnovation, Technological Dissemination and Marketing. Sustainability. 2014;6(5):2961-73.

6. Garcha H, Khanna P, Soni G. Nutritional importance of mushrooms. In: Chang S, Buswell J, Chiu S, editors. Mushroom biology and mushroom products Chinese University. Hong Kong: Chinese University Press; 1993.

7. Tibuhwa DD. Wild mushroom-an underutilized healthy food resource and income generator: experience from Tanzania rural areas. Journal of ethnobiology and ethnomedicine. 2013;9(1):49.

8. World Bank. Ethiopia: Country economic memorandum Geneva World Bank, 2004.

9. Dawit A. Mushroom Cultivation: A practical approach. Addis Ababa: Birhannaselam printing enterprise; 1998.

10. Oei P, van Nieuwenhuijzen B. Small-scale mushroom cultivation: oyster, shiitake and wood ear mushrooms. Wageningen, The Netherlands: Digigrafi; 2005.
11. Oei P. Mushroom cultivation: appropriate technology for mushroom growers: Backhuys Publishers; 2003.

12. Sarker N, Hossain M, Sultana N, Mian I, IJ SK, Ruhul Amin S. Effect of Different $\mathrm{pH}$ Levels on the Growth and Yield of $\mathrm{P}$. ostreatus (Jacquin ex Fr.) Kummer. Bangladesh Journal of Mushroom. 2007;1(1):57-67.

13. Stamets P. Growing gourmet and medicinal mushrooms: a companion guide to the mushroom cultivator. Hong Kong: Random House LLC; 2011.

14. Alam N, Lee J, Lee T. Mycelial growth conditions and phylogenetic relationships of Pleurotus ostreatus. World applied science journal 2010;9(8):928-37.

15. Nwokoye AI, Kuforiji O, Oni P. Studies on Mycelial Growth Requirements of Pleurotus Ostreatus (Fr.) Singer. International Journal of Basic and Applied Sciences. 2010;10(2):47-53.

16. Yildiz S, Yildiz ÜC, Gezer ED, Temiz A. Some lignocellulosic wastes used as raw material in cultivation of the $<\mathrm{i}>$ Pleurotus ostreatus $<$ i $>$ culture mushroom. Process Biochemistry. 2002;38(3):301-6.

17. Baysal E, Peker H, Yalinkiliç MK, Temiz A. Cultivation of oyster mushroom on waste paper with some added supplementary materials. Bioresource Technology. 2003;89(1):95-7.

18. Pant D, Reddy UG, Adholeya A. Cultivation of oyster mushrooms on wheat straw and bagasse substrate amended with distillery effluent. World Journal of Microbiology and Biotechnology. 2006;22(3):26775.

19. Ruiz-Rodriguez A, Soler-Rivas C, Polonia I, Wichers HJ. Effect of olive mill waste (OMW) supplementation to Oyster mushrooms substrates on the cultivation parameters and fruiting bodies quality. International Biodeterioration \& Biodegradation. 2010;64(7):638-45.

20. Marino RH, da Eira AF, Kuramae EE, Queiroz EC. Morphomolecular characterization of Pleurotus ostreatus (Jacq. Fr.) kummer strains in relation to luminosity and temperature of frutification. Scientia Agricola. 2003; 60(3): 531-535.

21. Zervakis G, Philippoussis A, Ioannidou S, Diamantopoulou P. Mycelium growth kinetics and optimal temperature conditions for the cultivation of edible mushroom species on lignocellulosic substrates. Folia microbiologica. 2001;46(3):231-4.

22. Sher H, Al-Yemeni M, Bahkali AH, Sher H. Effect of environmental factors on the yield of selected mushroom species growing in two different agro ecological zones of Pakistan. Saudi Journal of Biological Sciences. 2010;17(4):321-6.

23. Shah Z, Ashraf M, Ishtiaq M. Comparative study on cultivation and yield performance of oyster mushroom (Pleurotus ostreatus) on different substrates (wheat straw, leaves, sawdust). Pakistan Journal of Nutrition. 2004;3(3):158-60.

24. Prakash P, Aashish Bohra A, Neil J, Sivasubramnian. Effect of Humic Acid on Pleurotus Ostreatus Mushroom Cultivation and Analysis of Their Nutrient Contents. Research Journal of Agriculture and Biological Sciences. 2010;6(6):1067-70.

\section{How to cite this article:}

Asmamaw Tesfaw, Abebe Tadesse, Gebre Kiros. Optimization of oyster (Pleurotus ostreatus) mushroom cultivation using locally available substrates and materials in Debre Berhan, Ethiopia. J App Biol Biotech, 2015; 3 (01): 015-020. 